\section{Overcoming reductionism when linking climate variability with human history}

Ulf Büntgen ${ }^{1,2,3}$, A. Kirdyanov ${ }^{4,5}$, E. Vaganov ${ }^{4,5}$ and workshop participants ${ }^{6}$

Krasnoyarsk, Russia, 10-14 April 2017
Attended by 45 scholars from seven nations, this first PAGES $2 k$ Network workshop in the world's largest country took place at the Siberian Federal University in Krasnoyarsk, Russia. Timely aspects of archaeology, biogeochemistry, climatology, ecology, history, and epidemiology were catalyzed in 20 stimulating talks. Focusing on the available paleo-evidence from Inner Eurasia, the authors not only devoted critical discussion to data-inherent and methodological-induced limitations, but also prioritized future research avenues towards a better understanding of environmental and societal changes throughout much of the Holocene.
A cross-disciplinary mapping project was launched as a direct outcome of this meeting, with great enthusiasm from all participants expected to translate into a unique database. Considering the greater Altai region as a nucleus for sociocultural evolution, two geographical domains have been defined: A core region from $60-120^{\circ} \mathrm{E}$ and $40-60^{\circ} \mathrm{N}$, as well as a wider expanse from $30-150^{\circ} \mathrm{E}$ and $40-60^{\circ} \mathrm{N}$. Following on from the LALIA concept (Büntgen et al. 2016, 2017), the database will comprise information from archaeological findings, disease outbreaks, genetic structures, glacier dynamics, ice cores, lake sediments, pollen profiles, trade routes, tree rings, and written sources (Fig. 1). Output from externally forced, coupled climate-model simulations

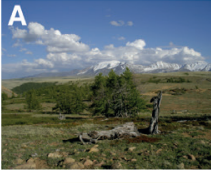

B

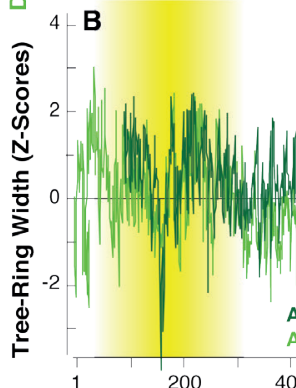

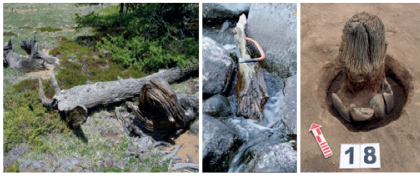

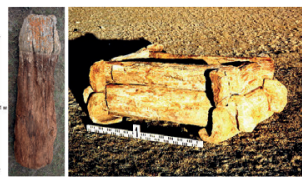

18
Alps 400

\section{LALIA}

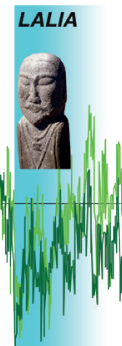

600

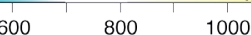

1000

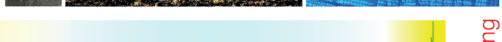

1

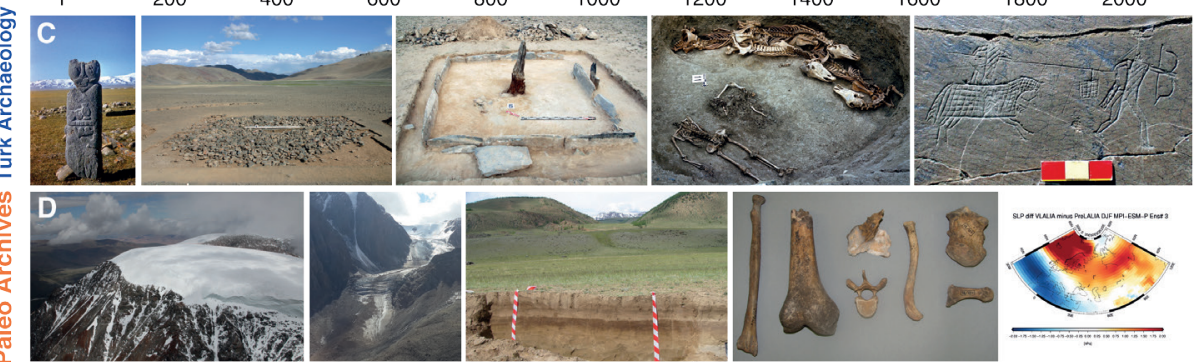

Figure 1: (A; left-right) Living and relict Larix sibirica (larch) 2330 m asl in the Mongun-Tayga mountains of the Russian Altai, subfossil larch wood at the treeline (both A. Kirdyanov), and within a glacier (A. Nazarov). Archaeological larch wood from a Türk memorial in Kyzyl-Shin and from a Scythian burial in the Ulandryk valley (I. Slyusarenko), radiocarbon dated to $\sim 1500$ and $\sim 2300 \mathrm{cal} B P$, respectively. Stained tree rings of a relict larch sample from the treeline (V. Myglan), with black dot referring to a cooling-induced growth depression after a large volcanic eruption in 536 CE (Churakova (Sidorova) et al. 2014). (B) Tree-ring width chronologies from the European Alps and the Russian Altai (Büntgen et al. 2016). (C; left-right) Türk sculpture from the Turu-Altai mountain steppe, Türk kurgan in the valley of Char-Jamaatyn-Gol in the Mongolian Altai (both G. Kubarev), Türk memorial (no 5) with its stone and wooden remains in Kyzyl-Shin, Russian Altai (I. Slyusarenko), Türk burial (kurgan 11) at Balyk-Sook I cemetery in the Russian Altai, as well as engraved worries at Zhalgyz-Tobe in the Russian Altai (both G. Kubarev). (D; left-right) Tsambagarav glacier in the Mongolian Altay (H. Machguth) where a $72 \mathrm{~m}$ long (and 6000-year old) ice core was drilled (M. Schwikowski), and Ak-Tru glacier in the northern Chuya mountain range of the Russian Altay (A. Kirdyanov). Soil profile within the Chuya river valley (A. Agatova). Material for DNA extraction (A. Pilipenko), and climate model simulation for the LALIA (E. Xoplaki). of the last 2000 years is anticipated to provide mechanistic understanding of the underlying processes of past climate dynamics and their potential direct and indirect influences on environmental conditions, as well as trends and extremes in the sociopolitical and economic behavior of ancient societies (Büntgen and Di Cosmo 2016). Operating across different spatiotemporal scales, our interdisciplinary approach aims to answer the question: "How did climate change affect the rise and demise of Eurasia's nomadic steppe empires?".

In addition to its long-term goal, the consortium-driven workshop appeared particularly timely, because the ongoing and predicted rate of environmental and climatic change not only implies urgent research needs, but also offers a wide arena for (re)activating collaborations between Russia and the international scientific community (Büntgen 2014). Despite a variety of economic and logistic challenges, as well as political and administrative caveats, the workshop will hopefully contribute to mitigate deterioration of Russia's academic landscape, and to facilitate access to, and exploring of, a wealth of unique paleoarchives (Büntgen et al. 2014). Scholars from all disciplines and countries are kindly invited to strengthen the momentum and join any follow-up action.

\section{AFFILIATIONS}

'Department of Geography, University of Cambridge, UK ${ }^{2}$ Swiss Federal Research Institute WSL, Birmensdorf, Switzerland

${ }^{3} \mathrm{Global}$ Change Research Centre and Masaryk

University, Brno, Czech Republic

${ }^{4}$ Sukachev Institute of Forest SB RAS, Krasnoyarsk, Russia ${ }^{5}$ Siberian Federal University, Krasnoyarsk, Russia ${ }^{6}$ List and picture of all workshop participants under: www.pastglobalchanges.org/calendar/ all-events/127-pages/1622-overc-reduc-altai-17

\section{CONTACT}

Ulf Büntgen: ulf.buentgen@geog.cam.ac.uk

\section{REFERENCES}

Büntgen U et al. (2014) Holocene 24: 627-630

Büntgen U (2016) Clim Res 70: 95-98

Büntgen U, Di Cosmo N (2016) Sci Rep 6: 25606 Büntgen U et al. (2016) Nature Geosci 9: 231-236 Büntgen U et al. (2017) Nature Geosci 10: 243 Churakova (Sidorova) et al. (2014) Glob Plan Change 122: $140-150$ 